\title{
A Five-Year Engagement
}

\author{
ABBY J. KINCHY \\ RENSSELAER POLYTECHNIC INSTITUTE \\ SHOBITA PARTHASARATHY ${ }^{2}$ \\ UNIVERSITY OF MICHIGAN \\ JASON DELBORNE ${ }^{3}$ \\ NORTH CAROLINA STATE UNIVERSITY
}

In late 2015, the Society for Social Studies of Science (4S) launched Engaging Science, Technology, and Society (ESTS) with a commitment to public engagement and open access publishing-without author processing charges (APC). As founding members of the ESTS editorial board, we are proud to celebrate the first five years of this journal, the vision of its founding editor, Daniel Lee Kleinman, and the talents of its founding managing editor, Katie Vann. This is an important moment to reflect on what ESTS has accomplished so far, both because the editorial team is changing and because, in times of turmoil, we are led to reflect on what we value in academic practice, including publishing. The COVID-19 pandemic, white supremacist violence, and the climate crisis are the defining features of 2020 (so far). ESTS reflects a set of values for scholarship that engages with the intensity of our world: timeliness, commitment to addressing and influencing public discussion, and engagement with audiences (and authors!) beyond our sometimes narrow intellectual circles.

ESTS was launched with a mission to encourage multiple genres of academic writing. These include classical research articles, review essays, and edited volumes (called "Thematic Collections"), as well as debates ("Debates/Interactions"), op-ed style essays ("Critical Engagements"), career reflections ("Traces"), and short-form entries on new concepts ("Considering Concepts"). As readers, reviewers, and authors, we have eagerly observed how STS scholars have made use of these new genres to comment on the pressing issues of our time. For instance, an exchange between Noortje Marres (2018) and Steve G. Hoffman (2018) grappled with the responsibilities and roles of STS in this political era, when commitments to truth seem so tenuous. This debate became the most-cited contribution in the journal's Debates/Interactions

'Abby J. Kinchy, Email: kincha@rpi.edu sShobita Parthasarathy, Email: shobita@umich.edu Jason Delborne, Email: jadelbor@ncsu.edu 
section. Further discussion of "post-truth" politics appears in the journal's most recent thematic collection on "STS in the Trump Era" and subsequent ESTS publications on this topic.

One novel article format, the "Considering Concepts" genre, has enabled authors to give thoughtful and rigorous, though brief, presentations of emerging theoretical work. Authors have a manageable yet meaningful opportunity to work through a concept in a peer-reviewed publication that functions to open a conversation rather than have the last word. To be sure, to encounter short-form expression in scholarly titles is no longer entirely unique. Blogging has found its place among scholarly communities, and blog-esque, non-peer-reviewed pieces have become increasingly common in some peer-reviewed journals read by STS scholars. What we find distinctive about Kleinman's and Vann's experimentation with the new genres of Critical Engagements and Considering Concepts in ESTS is that while these genres differ from classical research articles in format, every effort has been made to maintain the clear quality criteria, blind peer review, and rigor that are expected from classical, long-form peer-reviewed scholarship. Doing so has entailed working with reviewers and authors to think through—to experiment with and create--what it means to express rigorous scholarly practice in novel modes of representation. These editorial processes make sound STS scholarship distinctive in the vast landscape of emerging literatures, while creating openings for reaching new and different audiences.

As a recent example, Parvin and Pollock's (2020) “Unintended by Design: On the Political Uses of 'Unintended Consequences'" reaches deeply into STS pre-history to connect Merton's (1936) paper about "unanticipated consequences" to a modern discourse about "unintended consequences." The authors open their essay with a playful vignette: an imagined conversation between an "intrepid intersectional feminist scholar" and a proponent of "smart city" traffic control. The conversation reveals both the intellectual and emotional work of designating--and dismissing - the feminist's systemic concerns as "unintended consequences." The story resonates with those of us STS scholars who want to engage in shaping and influencing innovation but frequently find ourselves playing the "killjoy" and being ignored. Parvin and Pollack then leap from the vignette into an historical, political, metaphorical, and ideological exploration of the power and role of "unintended consequences." They conclude that the term "is a barrier to, rather than a facilitator of, vital discussions about design...[and] works to deny accountability, imagination, or commitment" (p. 326). By considering this concept in a playful and rigorous format in ESTS, Parvin and Pollock make a mark upon our STS brains; we will never be able to shrug off or leave unexamined the casual delegation of consequences of science and technology to the "unintended" realm.

Looking back over the last five years, the journal has published crucial articles on climate change, the COVID-19 pandemic, immigration policy, and emerging issues in our digital landscape. The journal's most-downloaded research articles all deal with information technology, suggesting that there is an audience eager for politically-relevant research on blockchain (Levy 2017), human-robot interaction (Elish 2019), and artificial intelligence (Campolo and Crawford 2020). Such issues seem especially pertinent in this time of Zoom meetings, online surveillance of students, telemedicine, and other new forms of digital interaction. 
Some of the most downloaded and cited publications in ESTS have grappled with questions about the future of our own field. For instance, the thematic collection titled "Positioning the Field: STS Futures," contains Ruha Benjamin's (2016) agenda-setting article (discussed further below), which as of this writing in 2020 has been downloaded nearly 2500 times. Another thematic collection, addressing the "dynamics of evaluation, measurement, and competition in contemporary academia" (Fochler and de Rijcke 2017) is the most cited in that genre. In that collection, it was especially eye-opening to read managing editor Katie Vann's (2017) article on the "journal impact factor" system, which includes this wise observation:

\begin{abstract}
...data-centric evaluation gives rise to losses for academic communities: over-reliance on a particular indicator has a way of foreclosing a range of scholarly contributions to recognition of their importance and efficacy in realizing the broader objectives of scholarly activities. That foreclosure renders valuable resources as waste and may have deleterious effects for academic communities over time. Those in academic leadership positions might find that the prospects of those effects make it worthwhile to consider ways of broadening evaluators' lines of sight, even as that broadening may limit the prospects of evaluative objectivity. Because maybe things can be different: what is now rendered waste could become beacons of value in the eyes of leadership (Vann 2017: 106).
\end{abstract}

As we look forward to the next chapter of ESTS, let us keep Vann's insights in mind as we continue to press for envisioning how "things can be different," even in a publishing world fixated on impact factors and $\mathrm{H}$-indexes.

Beyond the academic world, engaged STS scholars are part of a growing movement to make science and technology and their associated educational, industrial, and policy structures more equitable and just. ESTS has responded by publishing agenda-setting articles offering antiracist paths forward. Benjamin (2016) asks us to look beyond the racist dimensions of surveillance technologies to consider how tools that seem to serve helpful or liberatory purposes-from health care to education--actually reproduce "the very forms of classificatory stigma that restrict people's life chances in the first place" (p. 150). And she asks us to consider further how an "abolitionist consciousness" might be brought into scientific and technological development. How might we innovate if we try to cultivate human agency and freedom "with and against sciences and technologies"? Similarly, earlier this year Hatch (2020) underlined the limitations of STS's traditional analytic approaches for historically disadvantaged communities of color fighting for power and justice. While STS's genealogical and social constructionist approaches offer important insights for understanding how racial and other politics are embedded in science and technology, historically alienated communities of color need truths that help them survive and engage in a world fundamentally shaped by white supremacy. How can STS produce usable truths for these communities while maintaining its philosophical commitments? Hatch offers a way forward that innovates on David Bloor's symmetry principle. As we excavate the genealogy of facts, he argues provocatively, STS scholars must also "cultivate confidence that the interpretations [we're] making about social and scientific worlds have some basis in what actually happened" (p. 63). Contributions like Hatch's and Benjamin's don't just develop the field 
of science and technology studies, they also push the field to participate in the public discourse of creating a better and more just world.

Before we close, we want to celebrate the valuable and too often invisible labor that has made ESTS what it is today. The quality and originality of articles in many formats have been due, in no small part, to the care and excellence of the editorial process. Those of us who have published in ESTS can attest to the care that Kleinman and Vann have given to helping authors develop their work before and following formal peer review. They have taken pains to support junior scholars in particular, guiding them through revisions and ensuring timely reviews. While the realities of academic publishing mean rejecting some articles, prospective authors have been treated with kindness, respect, and encouragement through personalized communication. Double-blind peer reviews were organized efficiently, careful editing improved the quality of manuscripts, and Vann's attention to detail moved accepted articles to page proofs and publication quickly.

It would be hard to overstate Kleinman and Vann's skills and accomplishments as an editorial team. We are grateful for what they have built for STS-and the broader world with which we engage. As we look back, we are amazed at their logistical prowess: creating the first open-access, born-digital STS journal; experimenting with novel article formats; and establishing a culture of intellectual rigor, compassion for authors, and openness to a diversity of ideas. All with shoestring start-up investment costs and low ongoing annual costs that are sustainable for $4 \mathrm{~S}$ long-term, which is necessary for an open access, no APC journal.

We honor and appreciate their commitment, energy, and talents that have shaped ESTS thus far, and we hope that the incoming editorial collective and board will continue and expand upon their "engaging" precedent!

\section{References}

Benjamin, Ruha. 2016. "Catching our breath: critical race STS and the carceral imagination." Engaging Science, Technology, and Society 2: 145-156.

Campolo, Alexander, and Kate Crawford (2020) "Enchanted Determinism: Power without Responsibility in Artificial Intelligence." Engaging Science, Technology, and Society 6: 1-19.

Elish, Madeleine Clare. 2019. "Moral crumple zones: Cautionary tales in human-robot interaction." Engaging Science, Technology, and Society 5: 40-60.

Fochler, Maximilian, and Sarah De Rijcke. 2017. "Implicated in the indicator game? An experimental debate." Engaging Science, Technology, and Society 3: 21-40.

Hatch, Anthony Ryan. 2020. "Du Boisian Propaganda, Foucauldian Genealogy, and Antiracism in STS Research." Engaging Science, Technology, and Society 6: 58-65.

Hoffman, Steve G. 2018. "The Responsibilities and Obligations of STS in a Moment of Post-Truth Demagoguery." Engaging Science, Technology, and Society 4: 444-452.

Levy, Karen EC. 2017. "Book-smart, not street-smart: blockchain-based smart contracts and the social workings of law." Engaging Science, Technology, and Society 3: 1-15. 
Marres, Noortje. 2018. "Why we can't have our facts back." Engaging Science, Technology, and Society 4: 423-443.

Merton, Robert K. 1936. “The Unanticipated Consequences of Purposive Social Action." American Sociological Review 1, no. 6: 894-904.

Parvin, Nassim, and Anne Pollock. 2020. "Unintended by Design: On the Political Uses of

'Unintended Consequences.'" Engaging Science, Technology, and Society 6 (2020): 320-327.

Vann, Katie. 2017. "Surplus and Indicator." Engaging Science, Technology, and Society 3: 92-107. 